\title{
Effects of Controlling the AZO Thin Film's Optical Band Gap on AZO/MEH-PPV Devices with Buffer Layer
}

\author{
Jaehyoung Park, ${ }^{1,2}$ Ki-Chang Jung, ${ }^{1}$ Ari Lee, ${ }^{1}$ Hyojung Bae, ${ }^{1}$ Daehwa Mun, ${ }^{1}$ Jun-Seok Ha, ${ }^{1}$ \\ Young-Bu Mun, ${ }^{3}$ E. M. Han, ${ }^{1}$ and Hang-Ju Ko ${ }^{2}$ \\ ${ }^{1}$ Department of Advanced Chemicals and Engineering, Chonnam National University, Gwangju 500-757, Republic of Korea \\ ${ }^{2}$ Photovoltaic and Optoelectronic Device Center, Korea Photonics Technology Institute, Gwangju 500-460, Republic of Korea \\ ${ }^{3}$ THELEDS Co., Gwangju 506-253, Republic of Korea
}

Correspondence should be addressed to Jun-Seok Ha, jsha@jnu.ac.kr

Received 31 August 2011; Accepted 27 December 2011

Academic Editor: Bhushan Sopori

Copyright (C) 2012 Jaehyoung Park et al. This is an open access article distributed under the Creative Commons Attribution License, which permits unrestricted use, distribution, and reproduction in any medium, provided the original work is properly cited.

Organic/inorganic hybrid solar cells were fabricated incorporating aluminum-doped zinc oxide (AZO) thin films of varying optical band gap in AZO/poly(2-methoxy-5-(2'-ethyl-hexyloxy)-p-phenylene vinylene) structures. The band gaps were controlled by varying the flow rates of $\mathrm{Ar}$ and $\mathrm{O}_{2}$ used to deposit the AZO. Devices with CdS buffer layer were also fabricated for improved efficiency. The effects of AZO optical band gap were assessed by testing the $I-V$ characteristics of devices with structures of glass/ITO/AZO/MEH-PPV/Ag under AM1.5 illumination $\left(100 \mathrm{~mW} / \mathrm{cm}^{2}\right)$. Efficiency was improved about 30 times by decreasing the AZO optical band gap, except in devices deposited without oxygen. A power conversion efficiency of $0.102 \%$ was obtained with the incorporation of a CdS buffer layer.

\section{Introduction}

Organic/inorganic hybrid solar cells are promising for their low manufacturing costs, facile processing, and applicability in flexible devices. They incorporate organic polymers such as MEH-PPV and poly(3-hexylthiophene) (P3HT) that act as light absorbers and electron donors. Efficient separation of charge carriers from their place of generation in the light absorption layers depends on the electron properties of the inorganic material and the morphology of its interface with the polymer $[1,2]$. Therefore various inorganic semiconductors have been tested to improve efficiency; examples include cadmium selenide (CdSe) nanorods [3] and nanoparticles [4], cadmium sulfide (CdS) nanorods [5] and nanowires [6], $\mathrm{ZnO}$ thin film [7] and nanorods [8-10], and $\mathrm{TiO}_{2}$ nanoparticles [11]. Controlling the optical band gap of inorganic materials through the use of Al-doped zinc oxide (AZO) is also promising as these stable thin films have high electron mobility and affinity. ZnO/P3HT devices' efficiencies have been doubled upon the incorporation of a nanocrystalline CdS buffer layer that introduces a cascading energy band gap structure between the $\mathrm{ZnO}$ and P3HT [12].

This work reports improvement of PV performance by controlling the optical band gap of AZO in AZO/poly [2-methoxy-5-(2'-ethyl-hexyloxy)-p-phenylene vinylene] (MEH-PPV) devices. Furthermore, we introduced CdS thin-film buffer layer between AZO and MEH-PPV for improved efficiency.

\section{Experimental Methods}

Soda lime glass substrates were sequentially cleaned ultrasonically in acetone, isopropyl alcohol, and deionized water and dried in nitrogen gas. An indium tin oxide (ITO) transparent conductive oxide layer was deposited on each substrate by DC magnetron sputtering through a patterned shadow mask. The patterned ITO glass was annealed for 15 minutes by RTA under nitrogen and oxygen. The sheet resistance of the ITO conductive oxide was $30 \Omega / \square$, measured by four-point probe. $3 \mathrm{wt} . \%$ AZO targets were formed from 


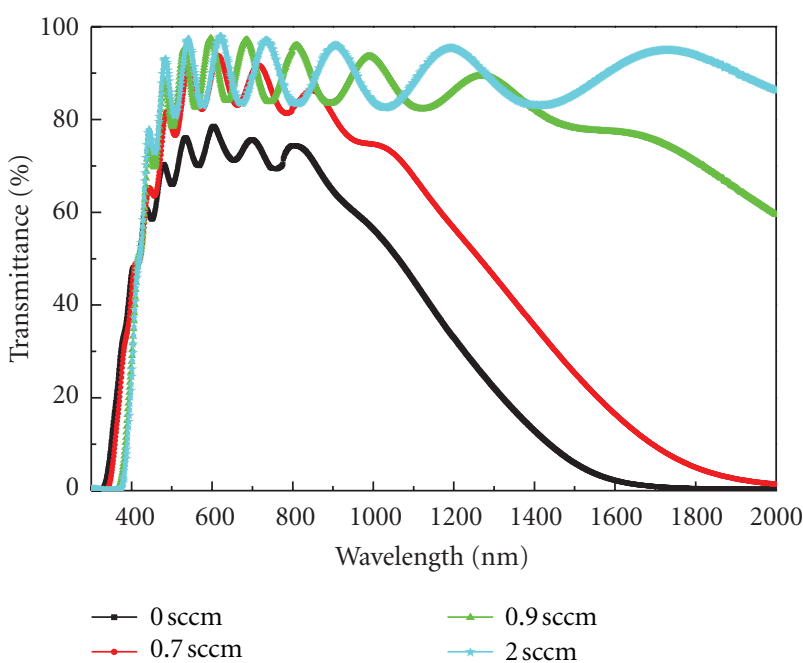

(a)

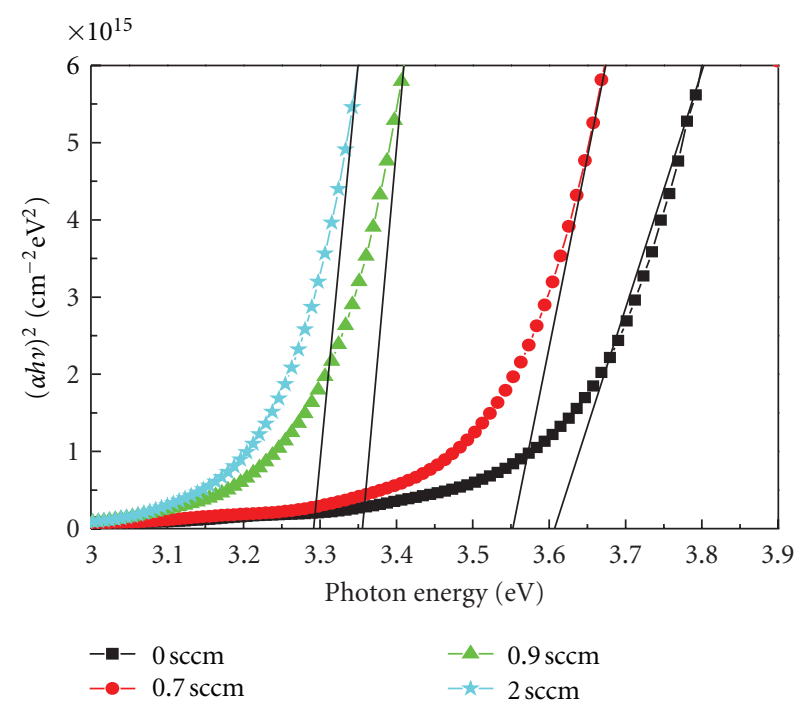

(b)

Figure 1: (a) Transmittance spectra of AZO thin films with various optical band gaps. (b) Evaluation of the AZO thin films' ( $\alpha h v)^{2}$ versus $h v$ curves.

high-purity $\mathrm{ZnO}(99.99 \%)$ and $\mathrm{Al}(\mathrm{OH})_{3}$ (99.99\%) powders. The AZO thin films' optical band gaps were controlled by varying the $\mathrm{O}_{2}$ and $\mathrm{Ar}$ gas mixture used during the RF magnetron sputtering. Ratios of the flow rates of argon and oxygen of $15: 0,14.3: 0.7,14.1: 0.9$, and $13: 2$ were used. CdS layers were deposited on the AZO thin films by RF magnetron sputtering under an $\mathrm{Ar}$ gas flow of $25 \mathrm{sccm}$. $10 \mathrm{mg}$ MEH-PPV polymer in $1 \mathrm{~mL}$ chloroform was then spin-coated as a thin film over the inorganic film. Ag anodes were deposited by electron beam evaporation under vacuum at below $4 \times 10^{-8} \mathrm{~Pa}$.

Scanning electron microscopy (SEM) was performed on a Hitachi S-4700 scanning electron microscope. Transmittance and absorption spectra were measured on a Cary 500 scan UV-Vis-NIR spectrophotometer. Photoluminescence spectra were recorded at room temperature under $325 \mathrm{~nm}$ $\mathrm{He}-\mathrm{Cd}$ laser excitation. Energy conversion efficiencies were measured under $100 \mathrm{~mW} / \mathrm{cm}^{2}$ illumination from an AM1.5 solar simulator.

\section{Results and Discussions}

Transmittances were measured between $300 \mathrm{~nm}$ and $2000 \mathrm{~nm}$ to assess the AZO samples' optical band gaps (Figure 1). In direct band gap semiconductors, intrinsic absorbance occurs near the band edge. Absorption coefficients were calculated using Lambert's law. The AZO thin films' optical band gaps were estimated by extrapolating the linear portions of plots $(\alpha h \nu)^{2}$ versus $h v$ using the relation $\alpha h v=A\left(h \nu-E_{g}\right)^{1 / 2}$, where $T$ is the transmittance, $t$ is the film's thickness, $\alpha$ is the absorption coefficient, $h v$ is the photon energy, $A$ is a constant, and $E_{g}$ is the direct optical band gap [13]. Optical band gaps of the AZO films deposited at argon and oxygen ratios of $15: 0,14.3: 0.7,14.1: 0.9$, and $13: 2$ were calculated to be
3.29, 3.35 3.54, and $3.61 \mathrm{eV}$, respectively. The optical band gap increased as the $\mathrm{O}_{2}$ partial pressure during deposition decreased due to $\mathrm{Al}$ ions being substituted into the $\mathrm{ZnO}$ lattice [14]. The AZO thin film showed an optical band gap of $3.29 \mathrm{eV}$, similar to that of intrinsic $\mathrm{ZnO}$. PV performances of the AZO thin films in devices with MEH-PPV generally increased as the AZO's optical band gap decreased, except in devices deposited without oxygen (Table 1). Sheet resistance, from Hall measurements, decreased from $1.08 \times 10^{6} \Omega / \square$ to $69.18 \Omega / \square$ as the optical band gap of the AZO increased. Concurrently, bulk carrier concentration increased from $-1.45 \times 10^{19} / \mathrm{cm}^{3}$ to $-6.73 \times 10^{20} / \mathrm{cm}^{3}$. Devices deposited without oxygen showed good charge collection because of low sheet resistance and high carrier concentration. As the AZO's optical band gap decreased, the electron barrier between the lowest unoccupied molecular orbital (LUMO) levels of MEH-PPV and AZO decreased [15].

Absorbances of the devices' layers were calculated from transmittance spectra; the PL spectrum of MEH-PPV was also measured (Figure 2). The optical absorption of MEHPPV film peaked at $500 \mathrm{~nm}$, showing an edge at $590 \mathrm{~nm}$ in the visible region. CdS thin film began to absorb slowly from around $550 \mathrm{~nm}$ to $490 \mathrm{~nm}$. The optical absorptions of AZO and intrinsic $\mathrm{ZnO}$ thin film were in the UV region. The PL spectrum of MEH-PPV thin film shows that photoinduced charge transfer occurred in the MEH-PPV thin film [16].

Previous insignificant PV performances have been attributed to the great electron barrier between the LUMO levels of MEH-PPV and AZO [15], and the movement of electrons to the cathode from charge carrier separation may have been limited. CdS thin films were used as buffer layers between the MEH-PPV and AZO. CdS thin film started to absorb slowly from around $550 \mathrm{~nm}$ to $490 \mathrm{~nm}$ (Figure 2). The optical band gap of CdS thin film was $2.2 \mathrm{eV}$. The CdS layer, with an optical band gap of $2.2 \mathrm{eV}$, created a cascading 
TABLE 1: Average PV performances of various AZO thin films in devices with MEH-PPV.

\begin{tabular}{lccccccc}
\hline Sample & $\mathrm{O}_{2}$ flow rate $(\mathrm{sccm})$ & Ar flow rate $(\mathrm{sccm})$ & optical band gap $(\mathrm{eV})$ & $J_{\mathrm{sc}}\left(\mathrm{mA} / \mathrm{cm}^{2}\right)$ & $V_{\text {oc }}(\mathrm{V})$ & $\mathrm{FF}(\%)$ & $\mathrm{PCE}(\%)$ \\
\hline 1 & 0 & 15 & 3.61 & 0.371 & 0.16 & 25.54 & 0.019 \\
2 & 0.7 & 14.3 & 3.54 & 0.147 & 0.012 & 23.12 & 0.001 \\
3 & 0.9 & 14.1 & 3.35 & 0.234 & 0.116 & 24.36 & 0.008 \\
4 & 2 & 13 & 3.29 & 0.321 & 0.264 & 28.19 & 0.03 \\
\hline
\end{tabular}

TAble 2: Average PV performances of AZO/CdS/MEH-PPV and AZO/MEH-PPV devices.

\begin{tabular}{lcccc}
\hline Sample & $J_{\text {sc }}\left(\mathrm{mA} / \mathrm{cm}^{2}\right)$ & $V_{\mathrm{oc}}(\mathrm{V})$ & $\mathrm{FF}(\%)$ & $\mathrm{PCE}(\%)$ \\
\hline $\begin{array}{l}\text { AZO/MEH-PPV } \\
\begin{array}{l}\text { Device with buffer } \\
\text { layer }\end{array}\end{array}$ & 0.321 & 0.264 & 28.19 & 0.03 \\
\hline
\end{tabular}

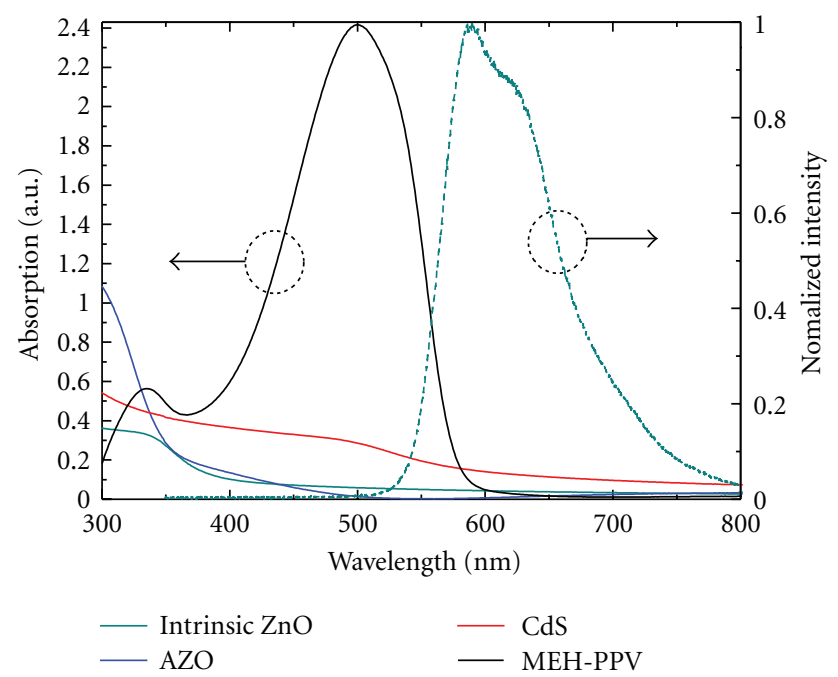

Figure 2: Absorption spectra of intrinsic $\mathrm{ZnO}, \mathrm{AZO}, \mathrm{CdS}$, and MEH-PPV thin film (left). PL spectrum of MEH-PPV thin film (right).

energy band gap structure between the AZO and MEH-PPV (Figure 3(a)) in the device structure that was characterized by SEM (Figure 3(b)).

The $I-V$ behaviors of AZO/MEH-PPV bilayers were compared with AZO/CdS/MEH-PPV devices (Figure 4 and Table 2). AZO layers of $3.29 \mathrm{eV}$ optical band gap were used as they resulted in the highest energy conversion efficiency (Table 1). $V_{\text {oc }}$ and $J_{\text {sc }}$ were doubled in the device with a CdS buffer layer under simulated AM1.5 illumination (Figure 4). These results were attributed to the cascading energy band gap structure of the CdS between AZO and MEH-PPV. This CdS layer could be photoexcited to produce additional photocurrent to improve energy efficiency, similar to in the $\mathrm{AZO}$ and MEH-PPV layers [9].

\section{Conclusions}

The PV efficiency of MEH-PPV/AZO hybrids could be increased by controlling the optical band gap of the AZO (a) Vacuum level

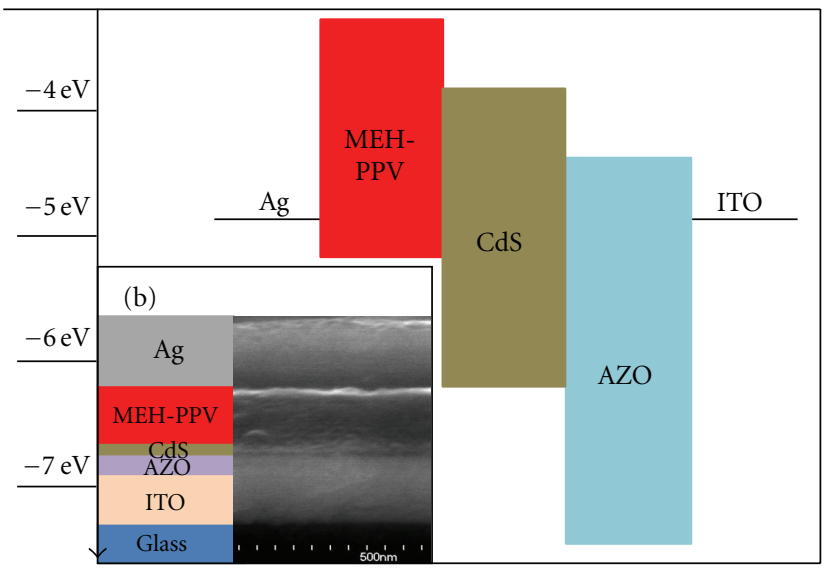

Figure 3: (a) An energy band diagram. (b) The AZO/CdS/MEHPPV device and its cross-section SEM image.

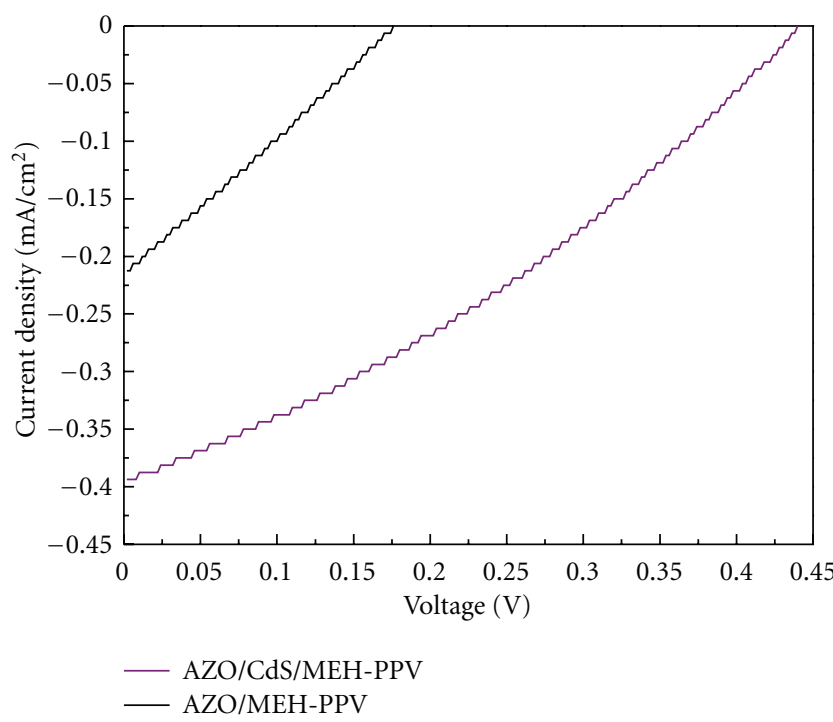

Figure 4: $I-V$ characteristics of $\mathrm{AZO} / \mathrm{CdS} / \mathrm{MEH}-\mathrm{PPV}$ and $\mathrm{AZO} / \mathrm{MEH}-\mathrm{PPV}$ devices.

thin film. Addition of a CdS buffer layer also significantly improved PV efficiency. These results demonstrate that controlling the optical band gap of $\mathrm{ZnO}$ and hybrid organic/inorganic solar cells with buffer layers can provide promising improvements to hybrid PV technologies. 


\section{Acknowledgments}

This research was financially supported by the Ministry of Education, Science Technology (MEST) and the National Research Foundation of Korea through the Human Resource Training Project for Regional Innovation.

\section{References}

[1] S. D. Oosterhout, M. M. Wienk, S. S. van Bavel et al., "The effect of three-dimensional morphology on the efficiency of hybrid polymer solar cells," Nature Materials, vol. 8, no. 10, pp. 818-824, 2009.

[2] S. D. Oosterhout, L. J. Koster, S. S. van Bavel et al., "Controlling the morphology and efficiency of hybrid $\mathrm{ZnO}$ :polythiophene solar cells via side chain functionalization," Advanced Energy Materials, vol. 1, no. 1, pp. 90-96, 2011.

[3] W. U. Huynh, J. J. Dittmer, and A. P. Alivisatos, "Hybrid nanorod-polymer solar cells," Science, vol. 295, no. 5564, pp. 2425-2427, 2002.

[4] A. M. Peiro, P. Ravirajan, K. Govender et al., "Hybrid polymer/metal oxide solar cells based on $\mathrm{ZnO}$ columnar structures," Journal of Materials Chemistry, vol. 14, p. 1087, 2004.

[5] D. C. Olson, J. Piris, R. T. Collins, S. E. Shaheen, and D. S. Ginley, "Hybrid photovoltaic devices of polymer and $\mathrm{ZnO}$ nanofiber composites," Thin Solid Films, vol. 496, no. 1, pp. 26-29, 2006.

[6] S. H. Choi, H. Song, I. K. Park et al., "Synthesis of sizecontrolled CdSe quantum dots and characterization of CdSeconjugated polymer blends for hybrid solar cells," Journal of Photochemistry and Photobiology A, vol. 179, no. 1-2, pp. 135141, 2006.

[7] L. Wang, Y. Liu, X. Jiang, D. Qin, and Y. Cao, "Enhancement of photovoltaic characteristics using a suitable solvent in hybrid polymer/multiarmed CdS nanorods solar cells," Journal of Physical Chemistry C, vol. 111, no. 26, pp. 9538-9542, 2007.

[8] T. Yang, W. Cai, D. Qin et al., "Solution-processed zinc oxide thin film as a buffer layer for polymer solar cells with an inverted device structure," Journal of Physical Chemistry C, vol. 114, no. 14, pp. 6849-6853, 2010.

[9] D. Bi, F. Wu, M. Wang et al., "Device performance correlated with structural properties of vertically aligned nanorod arrays in polymer/ZnO solar cells," Journal of Physical Chemistry C, vol. 114, no. 32, pp. 13846-13852, 2010.

[10] M. Wang and X. Wang, "P3HT/ZnO bulk-heterojunction solar cell sensitized by a perylene derivative," Solar Energy Materials and Solar Cells, vol. 92, no. 7, pp. 766-771, 2008.

[11] T.-W. Zeng, Y. Y. Lin, H. H. Lo et al., "A large interconnecting network within hybrid $\mathrm{MEH}-\mathrm{PPV} / \mathrm{TiO}_{2}$ nanorod photovoltaic devices," Nanotechnology, vol. 17, no. 21, p. 5387, 2006.

[12] E. D. Spoerke, M. T. Lloyd, E. M. McCready, D. C. Olson, Y.J. Lee, and J. W. P. Hsu, "Improved performance of poly(3hexylthiophene)/zinc oxide hybrid photovoltaics modified with interfacial nanocrystalline cadmium sulfide," Applied Physics Letters, vol. 95, no. 21, Article ID 213506, 2009.

[13] K. Kuriyama, T. Kato, and T. Tanaka, "Optical band gap of the filled tetrahedral semiconductor LiZnN," Physical Review B, vol. 49, no. 7, pp. 4511-4513, 1994.

[14] K. A. Jeon, J. H. Kim, W. Y. Shim, W. Y. Lee, M. H. Jung, and S. Y. Lee, "Magnetic and optical properties of $\mathrm{Zn}_{1-\mathrm{x}} \mathrm{Mn}_{\mathrm{x}} \mathrm{O}$ thin films prepared by pulsed laser deposition," Journal of Crystal Growth, vol. 287, no. 1, pp. 66-69, 2006.
[15] P. P. Boix, J. Ajuria, G. Garcia-Belmonte et al., "Letter dynamics of bulk polymer heterostructure/electrolyte devices," The Journal of Physical Chemistry Letters, vol. 1, no. 22, pp. 32773282, 2010.

[16] H. J. Chen, L. Wang, and W. Y. Chiu, "Effects of annealing treatment on the properties of MEH-PPV/titania hybrids prepared via in situ sol-gel reaction," European Polymer Journal, vol. 43, no. 11, pp. 4750-4761, 2007. 


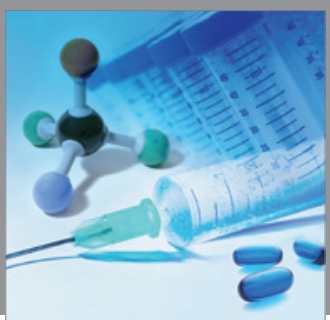

International Journal of

Medicinal Chemistry

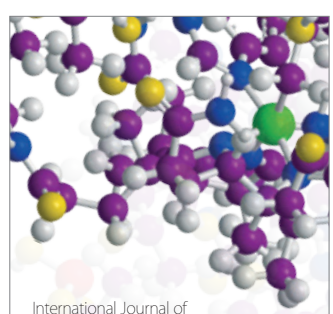

Carbohydrate Chemistry

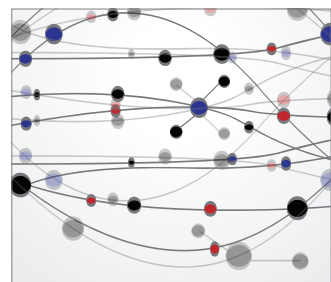

The Scientific World Journal
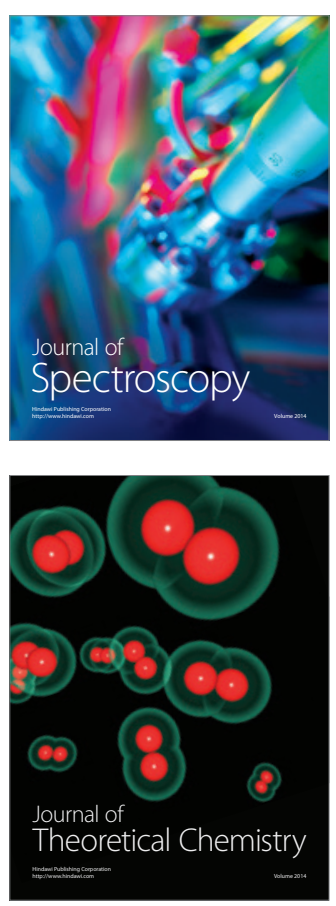
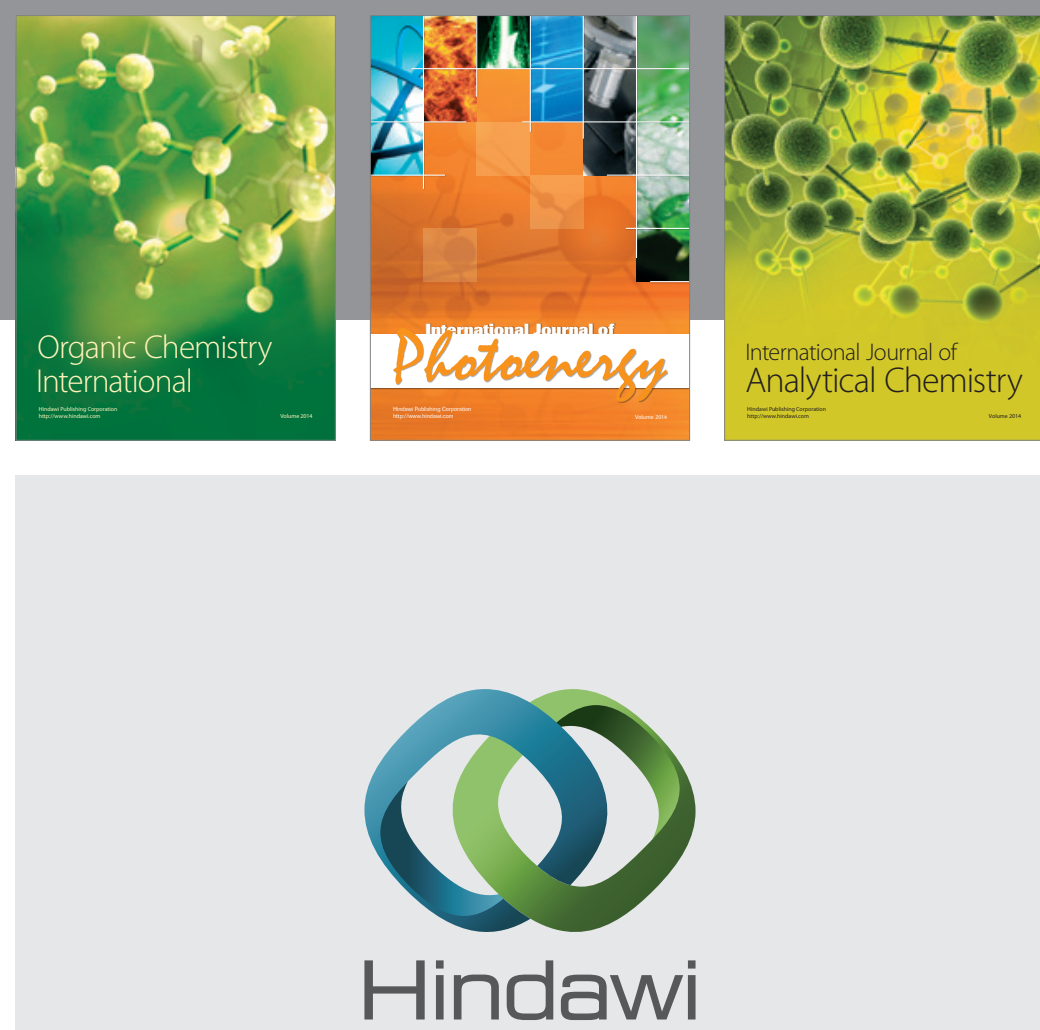

Submit your manuscripts at

http://www.hindawi.com
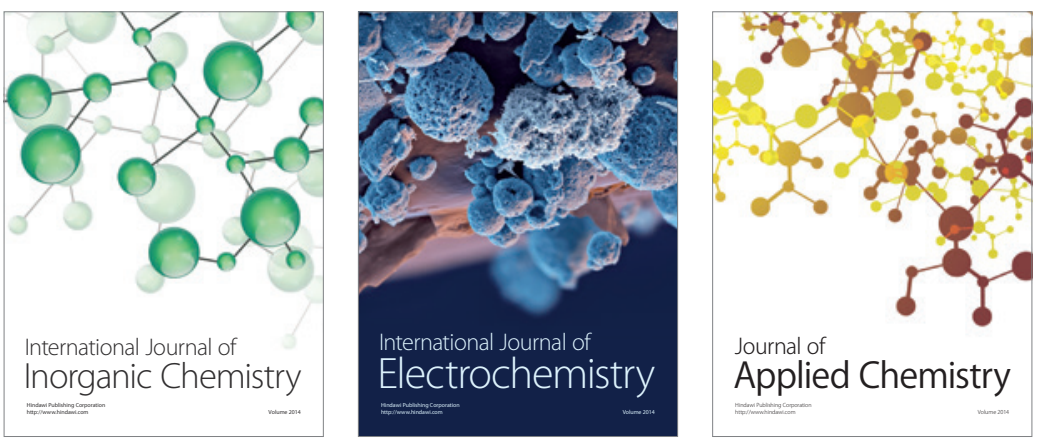

Journal of

Applied Chemistry
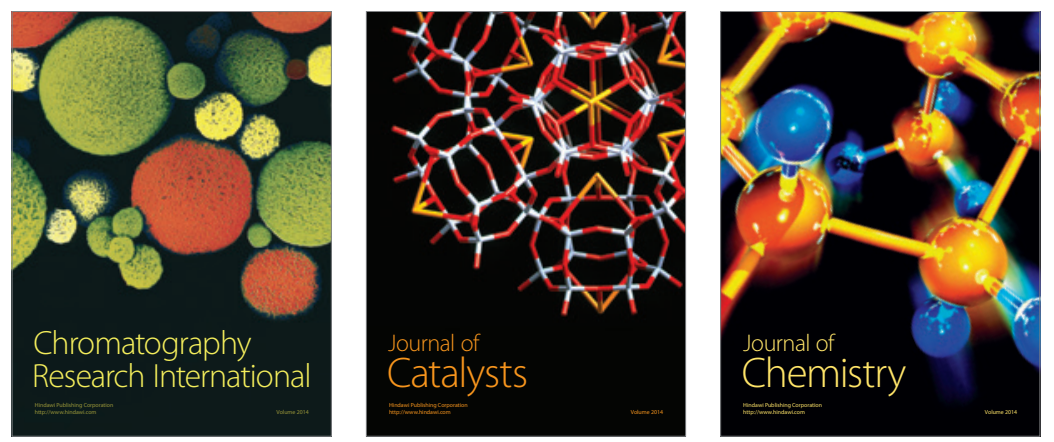
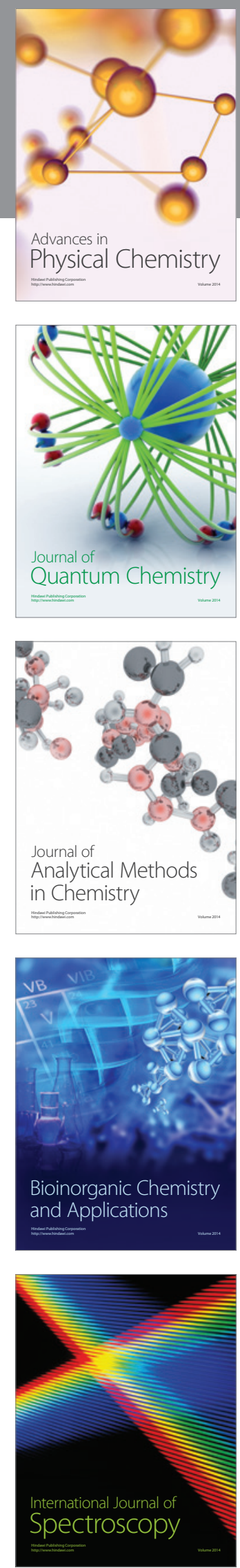